\title{
The research trends of Arts, Humanities and Social Sciences Research at the University of Zululand, 1994 - 2008
}

\author{
Dennis Ocholla and Janneke Mostert \\ Department of Information Studies, University of Zululand \\ Docholla@pan.uzulu.ac.za and jmostert@pan.uzulu.ac.za
}

\begin{abstract}
The Arts, Humanities and Social Sciences departments play a fundamental role in university education and in promoting the vision and mission of the University of Zululand. This paper explores definitions of Humanities and the Social Sciences, and the terms 'research' and 'research output', and examines the status and challenges of research management at the University of Zululand to evaluate research in the cited departments. A bibliometric method was used to analyse the trends and challenges of Humanities and Social Sciences research by using research data reflecting on ongoing and completed Arts, Humanities and Social Science research publications submitted by staff and students from $1994-2008$ to the university's Research Office. Data was analysed by categorising research output according to overall research publication by department, publication in accredited (SAPSE) journals by each department, author productivity, and research output by categories. Pearson's correlation analysis was applied to test whether there was any correlation between registered research projects and research publications. Results indicate that strong AH\&SS research engagement and publication exist at the university. Most research output was in the form of journal articles and conference papers. There was also growing postgraduate research output in the form of Masters and Doctoral dissertations. AH\&SS research is generally multidisciplinary in nature. We noted that the system for capturing completed Masters and Doctoral research reports at the university is inadequate. The paper raises other issues that are important for AH\&SS research and development.
\end{abstract}

Keywords: Research, research trends, humanities, social sciences, arts, humanities and social sciences, informetrics, University of Zululand

\section{Introduction}

The Arts, Humanities and Social Sciences and their similarities and differences are inherently easy to confuse. The Arts and Humanities are academic disciplines that focus on the human condition. They are distinct from the Social Sciences because of the research methods used (analytical, critical and/or speculative.). Examples of these disciplines include Ancient and Modern Languages, Literature, History, Philosophy, Religion, and the Visual and Performing Arts. Scholars working in the field of the Humanities are sometimes referred to as "humanists". Kuper and Kuper (1985) define the Social Sciences as: "The fields of scientific knowledge and academic scholarship that study social groups and, more generally, human society." Contemporary social science covers a much wider field of subjects such as Philosophy, History, Demography, Anthropology, Linguistics, Social Work, Sociology, Political Sciences, Psychology, Media Studies and Cultural Studies, and Library and Information Sciences (LIS); scholars working in these disciplines are commonly referred to as "social scientists". The institutionalisation of the disciplines related to the Social Sciences only occurred in the last millennium. Although the origin of modern science has deep roots in the Arts, Humanities and Social Sciences, it has taken many years and a lot of convincing to get the orthodox academic community, who only recognised the Applied and Natural Sciences as 'sciences', to admit modern Arts, Humanities and Social Sciences into the field or family of 'science'.

Research output, how it is measured, and what measurement indicators and tools are acceptable, is still highly debated by members of the scholarly community. Research output is defined as the "textual output where research is understood as original [...] systematic investigation undertaken in order to gain new knowledge and understanding"5. With respect to the measurement of research output, there are those who are in favour of qualitative measures of research (e.g. Gorman, 2000; Calvert and Gorman, 2002) and strong proponents of peer review as a measure of research quality (e.g. Harnad, 1995). Similarly, there are those who favour the quantitative measurement of research impact using indicators such as citation analysis and the journal impact factor (e.g. Garfield, 1971, 1972, 1994, and 1998). For example, when defending the qualitative measures of journal quality as opposed to quantitative measures based on citedness or the impact factor, Calvert and Gorman have argued that: "The fact that paper $\mathrm{x}$ is cited $\mathrm{y}$ times is not an indicator of quality, but rather that it is cited - it is available, it is in the journal held by many libraries, the author (or publisher or editor) is particularly good at self-promotion" (Calvert and Gorman, 2002:I). Harnad (1995) is strongly in favour of peer review. In one of his seminal articles on the topic (Harnad, 1998: paragraph one) he argues that journals should not be free from the "process of peer review, whose 'invisible hand' is what maintains its quality". Put another way, scientific or scholarly

5. Dennis Ocholla, PhD, is Professor and Head of the Department of Information Studies as well as Vice Dean, Faculty of Arts, University of Zululand, South Africa. Janneke Mostert, PhD, is a Senior Lecturer in the Department of Information Sudies at the University of Zululand, South Africa. 
output should not be exempt from the process of peer review for validation and approval for circulation and use by the scholarly community. The use of publication count analysis is widely used for the quantitative measurement of research output. However, counting alone without qualitative analysis does not provide an outcome that is reliable. Some of the limitations of publication count that have been widely noted over the years (e.g. King, 1987; Sengupta, 1992; Kostoff, 200 I; Moed, 2005; Schmoch and Schubert, 2009) include the argument that studies that use publication count do not measure the quality of research output; the approach is exclusive; the method does not account for contextual variations; publication count doesn't account for the size of the publications (i.e. short or long publications); and the approach doesn't account for the multi-dimensional nature of scientific activity. Despite these reservations, the method is still popular because it provides general and quick answers when measuring the research performance of individuals in a field, of institutions and the units within them, and of countries, which is fundamental for rapid decision making. In South Africa, for example, publication count (http://www.mth.uct.ac.za/ResearchOutput/guide_to_publication_cnt.html) is used, among other things, as: “... an annual compilation of the university's research output, which is submitted to the Department of Education to inform its allocation of government subsidy to the university every year". Increasingly, publication count as a descriptive bibliometrics method is triangulated with analytical informetric methods, such as citation analysis, in order to produce and obtain more reliable and robust results and avoid measurement biases (Moed, 2005; Schmoch and Schubert, 2009)

Scientometrics (quantitative measurement of science and scientific output), informetrics (quantitative measurement of information and information output), bibliometrics (quantitative measurement of records/recorded information and their output) and webometrics (quantitative measurement of web-based information and records and their output) provide methods for the quantitative measurement of research output and impact. Support for these methods is reflected in the activities of the International Scientometrics and Informetrics Association which has been organising ISSI conferences biennially since 1960. It is also reflected in the phenomenal support received from Thompson Reuters (popularly known as ISI) and through publications in mainstream domain journals such as Scientometrics and the Journal of Informetrics over the years. Increasingly, we note that research processes and research output undergo stages of validation through peer review before being accepted for funding, registration/acceptance, qualifications (e.g. Masters and Doctorates), and publication in scholarly outlets (e.g. journals).

There does not seem to be any consensus on the best way to measure research output in a given discipline; most members of the scientific community, particularly those in favour of quantitative measures of research such as Garfield (1994, 1998) and Harnad (1995, 1998) concur that peer-refereed journals offer a verifiable platform or source of measuring the research productivity of scholars. Each country, and in some cases institution, determines the quality of its research in different ways. Although other forms of research output, such as books, conference proceedings, reviews, theses and dissertations, patents, and other research reports of limited circulation, are used to measure research output, journal articles are still the most dominant, favoured and easily verifiable for quality control in scientific research. For example, quality research output in South Africa would most likely appear in a prescribed list of (currently 200) South African scholarly journals*, the Thompson Reuters (ISI) databases SCl, SSCl and $\mathrm{AHCl}$ [see http://www.isinet.com/isi/ journals/index.htm/], and the International Bibliography of Social Sciences (IBSS) databases [see http://www.lse.ac.uk/ collections/IBSS/access/Default.htm]. This would not include correspondence with the editors, abstracts or extended abstracts, obituaries, book reviews, news articles and advertorials. For each research article published in any journal indexed in the aforementioned lists or services, a substantial government research subsidy - which is regularly revised and increased - is paid to the author's affiliate institution, which then decides how to share the subsidy with the author(s)/ contributor(s).

The criteria for recognised research output in South Africa as published in 2003 in the "Policy and Procedure for Measurement of Research Output for Public Higher Education institutions"(see http://www.education.gov.za/Documents/ policies/PolicyMeasurementResearch.pdf), whose purpose it "... is to encourage research productivity by rewarding quality research output at public higher education institutions”, specifies eligibility for subsidisation for journals, books and proceedings in sufficient detail.

\section{Purpose of the paper}

This paper explores definitions of Humanities and the Social Sciences and the terms 'research' and 'research output', and examines the status and challenges of research management at the University of Zululand to evaluate research in the cited fields. The paper answers the following research questions: what are the Humanities, Social Sciences and research output? How is research managed at the University of Zululand? What is the overall research output of the Faculty of Arts? What is the publication output in SAPSE accredited journals? What is the number and distribution of registered research projects by each department? What is the publication output by author? Is there any relationship between

Inkanyiso, Jnl Hum \& Soc Sci 2010, 2(I) 
research registration and publication output? And what are the sources of AH\&SS publications in which the faculty publishes?

\section{Research management at the University of Zululand}

Research at the University of Zululand is managed by the Office of the Vice Rector of Academic Affairs and Research through the Senate Research Committee. The Committee is charged with the responsibility of formulating, coordinating and monitoring research policy and implementation. The Research Committee, which is normally chaired by the Vice Rector of Academic Affairs and Research, consists of two senate representatives, two council representatives, and four faculty representatives. The Research Office deals with day to day implementation. The university has a draft research policy, research website, and research administrator. The Research Office maintains a research database for ongoing and completed research as well as submitted research publications or output by staff and students. Research management within faculties is one of the key focus areas of all the Executive Deans of the various faculties. Increasingly, faculties appoint research officers or coordinators to coordinate research activities within their faculties. Staff members are required to register their research projects with the university and submit copies of all research output to the Research Office for recording and processing. However, not all staff members register their research projects with the university, particularly projects that are not funded by the university.

\section{Method and data collection}

We applied several methods and techniques for data collection. The literature review and our professional experiences and observations were used to conceptualise and contextualise the study. Quantitative content analysis through informetrics was used to analyze and demonstrate the status and trends of AH\&SS research in the Faculty of Arts. This was achieved by using research data reflecting on ongoing and completed AH\&SS registered research publications by staff and students in the Faculty of Arts from 1994 to 2008 based on research records captured and originating from the university's Research for the period. The period (1994 - 2008) was selected conveniently, although it falls within the period of South Africa's new political dispensation. The research database for registered research projects generally captures the researcher, department, faculty, project code, project status (i.e. whether active or not), and the project title. The publication data captures the name of the author, journal (year of publication, volume, pages, etc.), publication status (i.e. whether SAPSE-accredited or not), department, faculty, title, and other variables. Only the AH\&SS publications by staff affiliated to departments in the Faculty of Arts at the university were selected. Data was quantitatively analysed by categorising research output by each of the variables outlined in the research questions, following some of the recent data analysis techniques employed by Ocholla and Ocholla (2007), Onyancha and Ocholla (2009), and Ocholla and Onyancha (2009). Pearson's correlation analysis was used to test whether there was any correlation between registered research projects and publications.

\section{Results and discussion}

The results and discussion are presented under Sections 5.1 to 5.6 below.

5.1 Faculty of Arts research publication output, $1994-2008$

Research publication output refers to all the publications submitted by staff and students and captured by the university's Research Office from 1994 - 2008. These publications would normally include conference papers, journal articles, chapters in books, and books. Publication records were captured from 21 departments and centres that constitute the Faculty of Arts from 1994 to 2008 . A total sum of 965 records was published by all the departments. The four top ranked departments with the highest publication output were Library and Information Science (219), English (169), Theology (I5I), and Psychology (86). The English department's publication output was the steadiest during this period. Library and Information Science increased its output significantly from 2002 to 2008. This is also when the LIS department increased collaboration or co-authorship between staff and students and produced its first doctoral student. Before then, singleauthored publications predominated. The English Department's steady publication output could be attributed to the presence of senior academics, low staff turnover, and perhaps competition for promotion. We noted that publication output was closely related to the productivity of staff members, postgraduate (Masters and Doctoral) student enrolment (e.g. Library and Information Science and Psychology), participation in conferences, and co-authorship/collaboration among staff members (e.g. Psychology) or between staff and students (Library and Information Science). Many of the departments with lower outputs, especially in recent years (such as History and Afrikaans), were affected by reduced staff or the absence of postgraduate research capacity that could invariably contribute towards improved publication output. Academic promotion is also another incentive for greater publication output.

Inkanyiso, Jnl Hum \& Soc Sci 2010, 2(I) 
Table I Arts Faculty overall publication output for $1994-2008$

\begin{tabular}{|c|c|c|c|c|c|c|c|c|c|c|c|c|c|c|c|c|c|}
\hline Department & 94 & 95 & 96 & 97 & 98 & 99 & 0 & I & 2 & 3 & 4 & 5 & 6 & 7 & 8 & Sum & Rank \\
\hline Library \& Information Science & 2 & 4 & 2 & 2 & 6 & 3 & I & 5 & 18 & 14 & 12 & 40 & 26 & 49 & 36 & 220 & 1 \\
\hline English & 12 & 8 & 14 & 8 & 14 & 11 & 6 & II & 8 & II & 12 & 10 & 10 & 21 & 14 & 170 & 2 \\
\hline Theology & 16 & 5 & 15 & 13 & 44 & 9 & 6 & 3 & 4 & 4 & 10 & 15 & 5 & 3 & 2 & 154 & 3 \\
\hline Psycho-logy & 4 & 1 & 3 & 0 & 3 & 3 & 3 & 8 & 7 & 2 & 10 & 9 & 7 & 16 & 10 & 86 & 4 \\
\hline Criminal Justice & 1 & 0 & 1 & 0 & 1 & 0 & 0 & 2 & 3 & 8 & 1 & 5 & I & 7 & 33 & 63 & 5 \\
\hline Communication Science & 2 & 2 & 3 & 1 & 2 & 6 & 2 & 4 & 4 & 8 & 3 & 7 & I & 5 & 4 & 54 & 6 \\
\hline Afrikaans & 6 & 3 & 4 & 8 & 2 & 5 & 1 & 2 & 0 & 2 & 0 & 0 & 1 & 0 & 1 & 35 & 7 \\
\hline General Linguistics & 2 & 2 & 2 & 1 & 0 & 3 & 2 & 4 & 4 & 2 & 1 & 2 & 1 & 3 & 3 & 32 & 8 \\
\hline History & 5 & 0 & 2 & 3 & 3 & 2 & 1 & 0 & 0 & 2 & 2 & 1 & 0 & 2 & 3 & 26 & 9 \\
\hline Philosophy & 4 & 2 & 1 & 1 & 2 & 2 & 0 & 0 & 2 & 2 & 0 & 6 & 2 & 1 & 1 & 26 & 10 \\
\hline Anthropology \& Development & 0 & 0 & 0 & 0 & 0 & $\mathrm{I}$ & 2 & 0 & 3 & 1 & 2 & 3 & 3 & 5 & & 20 & II \\
\hline IsiZulu & 0 & 2 & 2 & 0 & 1 & 2 & 2 & 0 & 1 & 1 & 0 & 0 & 2 & 4 & 0 & 17 & 12 \\
\hline Centre for Arts \& Culture/Drama & 0 & 2 & 2 & 2 & 2 & 1 & 0 & 0 & I & 1 & 0 & 1 & I & 0 & 0 & 0 & 13 \\
\hline Sociology & 0 & 1 & 1 & 2 & 3 & 0 & 1 & 0 & 2 & 1 & $\mathrm{I}$ & 0 & 0 & 0 & 0 & 12 & 14 \\
\hline German & 0 & 2 & 2 & 0 & 3 & 0 & 0 & 0 & 0 & 0 & 0 & 1 & 2 & 0 & 1 & 11 & 15 \\
\hline Recreation \& Tourism & 0 & 0 & 0 & 0 & 0 & 0 & 0 & 0 & 0 & 0 & 0 & 1 & 2 & 1 & 6 & 10 & 16 \\
\hline IsiZulu Language & 0 & 0 & 0 & 0 & 1 & 0 & 0 & 0 & 0 & 0 & 0 & 0 & 0 & 7 & 0 & 8 & 17 \\
\hline Social Work & 0 & 2 & 1 & 0 & 1 & $\mathrm{I}$ & 0 & 0 & 1 & 0 & 0 & 0 & 0 & 1 & 0 & 7 & 18 \\
\hline Zulu Dictionary Project & 0 & 0 & 0 & 0 & 1 & 0 & 0 & 0 & 0 & 0 & 0 & 0 & 0 & 0 & 0 & 1 & 19 \\
\hline Total & 54 & 36 & 55 & 41 & 89 & 49 & 27 & 39 & 58 & 59 & 54 & 101 & 64 & 125 & 114 & 965 & \\
\hline
\end{tabular}

\subsection{Publications with SAPSE accreditation}

Publications that qualify for government or Department of Education subsidies, otherwise known as South African Post Secondary Education (SAPSE) publications, are those that appear in peer-refereed journals indexed by ISI, IBSS, and the South African prelisted journals mentioned earlier. They also include all other publications that qualify for such a subsidy (see Section 2.2). Such publications are expected to be rigorous, of high quality, and in the interest of promoting research and the development needs of the country. A substantive government subsidy is given to the institution of the author's affiliation for each qualifying publication. [This is normally counted in units. For example, one journal article is equivalent to one unit.] SAPSE publications play a significant role in the promotion of academic staff at the university.

Table 2 Arts Faculty SAPSE publications, $1994-2008$

\begin{tabular}{|c|c|c|c|c|c|c|c|c|c|c|c|c|c|c|c|c|}
\hline Department & 94 & 95 & 96 & 97 & 98 & 99 & 00 & OI & 02 & 03 & 04 & 05 & 06 & 07 & 08 & Total \\
\hline English & 10 & 5 & 6 & 8 & 8 & 7 & 0 & 6 & 5 & 9 & 7 & 4 & 6 & $1 \mathrm{II}$ & 8 & 100 \\
\hline Library \& Information Science & $\mathrm{I}$ & 0 & 4 & $\mathrm{I}$ & 5 & 2 & $\mathrm{I}$ & 4 & 6 & 7 & 10 & 16 & 8 & 9 & II & 85 \\
\hline Theology & 13 & 4 & 4 & 5 & 6 & 2 & 3 & 3 & 3 & 4 & 8 & 12 & 2 & 0 & $\mathrm{I}$ & 70 \\
\hline Psychology & 0 & I & 0 & $I$ & 0 & 0 & 2 & 3 & 5 & 2 & 10 & 7 & 5 & 12 & 8 & 56 \\
\hline Afrikaans & 3 & 3 & 4 & 5 & $\mathrm{I}$ & 5 & I & 2 & 0 & I & 0 & 0 & I & 0 & I & 27 \\
\hline Criminal Justice & 0 & 0 & I & 0 & I & 0 & 0 & 2 & I & 5 & I & 5 & 0 & 3 & 6 & 25 \\
\hline Communication Science & 1 & I & 3 & 1 & 0 & 1 & $\mathrm{I}$ & 0 & 4 & 7 & 0 & 0 & 0 & 3 & 2 & 24 \\
\hline Philosophy & 0 & I & 0 & 1 & 2 & 0 & 0 & 0 & 2 & 2 & 0 & 5 & 2 & 2 & 0 & 17 \\
\hline General Linguistics & 0 & 2 & $\mathrm{I}$ & $\mathrm{I}$ & 0 & 2 & 2 & 2 & 4 & 0 & I & 0 & 0 & 0 & I & 16 \\
\hline History & 2 & 0 & 2 & 3 & 2 & 0 & $\mathrm{I}$ & 0 & 0 & 1 & 2 & $\mathrm{I}$ & 0 & 0 & 2 & 16 \\
\hline Anthropology \& Development Studies & 0 & 0 & 0 & 0 & 2 & 1 & $\mathrm{I}$ & 0 & 2 & 1 & $\mathrm{I}$ & $\mathrm{I}$ & 2 & 0 & 0 & II \\
\hline Sociology & 0 & 0 & 0 & 0 & 2 & 0 & 1 & 0 & 2 & $\mathrm{I}$ & 1 & 0 & 0 & 0 & 0 & 7 \\
\hline IsiZulu & 0 & 2 & 2 & 0 & 0 & 0 & 1 & 0 & $\mathrm{I}$ & 0 & 0 & 0 & 0 & 0 & 0 & 6 \\
\hline Centre for Arts \& Culture & 0 & 3 & 0 & 0 & 0 & 1 & 0 & 0 & 0 & 0 & 0 & 1 & 0 & 0 & 0 & 5 \\
\hline Social Work & 0 & 2 & 0 & 0 & $\mathrm{I}$ & 0 & 0 & 0 & 1 & 0 & 0 & 0 & 0 & 0 & 0 & 4 \\
\hline German & 0 & I & 0 & 0 & 0 & 0 & 0 & 0 & 0 & 0 & 0 & 0 & 0 & 0 & 0 & 1 \\
\hline IsiZulu Language Research \& Development & 0 & 0 & 0 & 0 & 0 & 0 & 0 & 0 & 0 & 0 & 0 & 0 & 0 & 1 & 0 & 1 \\
\hline Zulu Dictionary Project & 0 & 0 & 0 & 0 & $\mathrm{I}$ & 0 & 0 & 0 & 0 & 0 & 0 & 0 & 0 & 0 & 0 & 1 \\
\hline Centre for Recreation \& Tourism & 0 & 0 & 0 & 0 & 0 & 0 & 0 & 0 & 0 & 0 & 0 & 0 & 0 & 0 & 0 & 0 \\
\hline Total & 30 & 25 & 27 & 26 & \begin{tabular}{|c|}
31 \\
\end{tabular} & 21 & 14 & 22 & 36 & 40 & 41 & 52 & 26 & 41 & 40 & 472 \\
\hline
\end{tabular}


English (93), LIS (86), Theology (70) and Psychology (56) were the leading departments. They were also the four leading departments in terms of overall publication output in more or less the same order, except that LIS produced the highest overall research output. Until 2004, Theology and Religious Studies was a fully fledged faculty at the university. Its output as a department in the Faculty of Arts since 2005 requires attention. Also worth highlighting is the inception of the Arts and Culture Centre in 2002 when the Departments of Drama and Music combined. Overall, there was a strong correlation between the overall departmental research publication and SAPSE publications.

\subsection{Registered projects per department}

To qualify for funding from the research committee, a research project has to be registered with the university and approved by the Research Committee. 307 research projects were registered in AH\&SS from 1994 - 2008, with a growth in the number of registered projects noted in the course of the last five years. Projects are categorised as departmental or Masters or Doctoral research. The distribution, trends and status of research registration are shown in Table 3.

Table 3 Overall registered research projects by departments, $1994-2008$

\begin{tabular}{|c|c|c|c|c|c|c|c|c|c|c|c|c|c|c|c|c|}
\hline Department & 94 & 95 & 96 & 97 & 98 & 99 & 00 & 0I & 02 & 03 & 04 & 05 & 06 & 07 & 08 & Total \\
\hline Afrikaans & 0 & 3 & 2 & I & 0 & 2 & 0 & 0 & 0 & 0 & 0 & 0 & 0 & I & 0 & 9 \\
\hline Anthropology \& Development Studies & 0 & 0 & I & 0 & 0 & I & 2 & 0 & 1 & I & $\mathrm{I}$ & 1 & 0 & 2 & 1 & 11 \\
\hline Centre for Arts \& Culture & 3 & 3 & 2 & 2 & $\mathrm{I}$ & $\mathrm{I}$ & 2 & 0 & 0 & $\mathrm{I}$ & 6 & 2 & $\mathrm{I}$ & $\mathrm{I}$ & 0 & 25 \\
\hline Centre for Recreation \& Tourism & 0 & 0 & 0 & 0 & 0 & 0 & 0 & 0 & 0 & 0 & 4 & 6 & $\mathrm{I}$ & $\mathrm{I}$ & 0 & 11 \\
\hline Communication Science & 0 & $\mathrm{I}$ & $\mathrm{I}$ & $\mathrm{I}$ & 0 & $\mathrm{I}$ & 0 & 0 & $\mathrm{I}$ & 2 & 3 & 2 & 3 & 2 & 2 & 19 \\
\hline Criminal Justice & 4 & 2 & 0 & 2 & 0 & 2 & 2 & $\mathrm{I}$ & 2 & $\mathrm{I}$ & 2 & 4 & 2 & 2 & 2 & 28 \\
\hline English & $\mathrm{I}$ & 2 & $\mathrm{I}$ & $\mathrm{I}$ & 6 & $\mathrm{I}$ & 2 & 0 & 0 & $\mathrm{I}$ & $\mathrm{I}$ & 4 & $\mathrm{I}$ & 2 & 3 & 26 \\
\hline General Linguistics & 0 & $\mathrm{I}$ & 0 & 0 & 0 & $\mathrm{I}$ & 0 & $\mathrm{I}$ & $\mathrm{I}$ & $\mathrm{I}$ & 2 & 1 & $\mathrm{I}$ & 2 & 0 & 11 \\
\hline German & 0 & $\mathrm{I}$ & 3 & 0 & 0 & 0 & 0 & 0 & 0 & 0 & 0 & 1 & 0 & 0 & 0 & 5 \\
\hline History & 0 & 0 & 0 & 2 & 1 & 0 & 0 & 0 & 0 & 0 & 0 & 0 & 0 & I & 0 & 4 \\
\hline IsiZulu & 0 & 1 & 3 & 3 & 0 & 0 & 2 & 0 & 5 & $\mathrm{I}$ & 0 & 1 & 2 & $I$ & 0 & 19 \\
\hline IsiZulu Language Research \& & 0 & 0 & 0 & 0 & 0 & 0 & 0 & 0 & 0 & 0 & 0 & 0 & 0 & 1 & 1 & 2 \\
\hline Library \& Information Science & 0 & 3 & I & $I$ & 2 & 5 & 2 & 6 & 5 & 2 & 3 & 5 & 7 & 12 & 1 & 55 \\
\hline Philosophy & 0 & 0 & 0 & $I$ & 0 & 0 & 0 & 0 & 0 & 0 & 0 & 0 & 0 & 2 & 1 & 4 \\
\hline Psychology & I & 1 & 0 & 3 & 0 & 0 & 0 & 4 & 0 & 0 & $I$ & 0 & $I$ & $I$ & 0 & 12 \\
\hline Social Work & 0 & 4 & 2 & 4 & I & I & 0 & $I$ & 3 & 0 & $I$ & 1 & 0 & 3 & 9 & 30 \\
\hline Sociology & 0 & 0 & 2 & $\mathrm{I}$ & 0 & 0 & 0 & 2 & 0 & I & 2 & 0 & 0 & 0 & 1 & 9 \\
\hline Theology & 3 & 2 & 2 & 3 & 3 & I & 0 & 0 & 0 & 0 & $I$ & 3 & 0 & 4 & 0 & 22 \\
\hline Zulu Dictionary Project & 0 & 0 & 0 & 0 & 0 & 0 & $\mathrm{I}$ & 0 & 0 & 0 & 0 & 0 & 0 & 0 & 0 & I \\
\hline Total & 12 & 24 & 20 & 25 & 14 & 16 & 13 & 15 & 18 & II & 26 & 31 & 19 & 36 & 21 & 303 \\
\hline
\end{tabular}

Departmental projects are research projects that are not registered for a formal qualification. Most such projects are based on individual or departmental research activities or undertakings by the academic staff for non-qualification purposes. A research project may be registered by more than one person if the work was collaborative or jointly authored. We counted such projects as one unit. Masters and Doctoral research projects are completed for qualification purposes and are therefore mainly registered by students, often with supervisors as research collaborators. As noted in Table 4 below, most research projects were departmental. It is highly possible that not all Masters and Doctoral research projects were registered by the university because the total number in the table is lower than our expectations. However, we did use the official university registrations as provided. The Department of LIS (55), Department of Social Work (30), Department of Criminal Justice (28), Department of English (26), and also the Centre for Arts and Culture (25) recorded the most registered research projects (see Tables 3 and 4). Library and Information Science was leading in postgraduate research registration in all three categories.

Data on the volume of registered research projects presented in Figure $I$ is quite surprising. We note that there were no significant differences between registered Masters and Doctoral research over the period, which is abnormal. Speculatively, as some verification is required, it is possible that course work Masters and Doctoral studies were not registered by the university because departments with the highest number of students and projects in that category, such as Social Work (mainly Masters) and Psychology (mainly Doctorate), had fewer registrations in this category (which we find unusual). The extreme polarity in the three categories of research registration, particularly for Masters and Doctoral registration, also warrants further investigation. 
Table 4 Registered research projects by department and categories

\begin{tabular}{|c|c|c|c|c|}
\hline Department & Dept. & Ms & D & Total \\
\hline Library \& Information Science & 27 & 13 & 15 & 55 \\
\hline English & 17 & 4 & 5 & 26 \\
\hline Social Work & 19 & 8 & 3 & 30 \\
\hline Criminal Justice & 18 & 4 & 6 & 28 \\
\hline Centre for Arts \& Culture/dram & 19 & 4 & 2 & 25 \\
\hline Afrikaans & 5 & 0 & 4 & 9 \\
\hline Communication Science & 8 & 5 & 6 & 19 \\
\hline Sociology & 4 & I & 4 & 9 \\
\hline Psychology & 6 & 5 & 1 & 12 \\
\hline IsiZulu & 6 & 5 & 8 & 19 \\
\hline Theology \& Religion Studies & 17 & 0 & 5 & 22 \\
\hline History & 4 & 0 & 0 & 4 \\
\hline Anthropology \& Development Studies & 7 & 3 & 1 & II \\
\hline Centre for Recreation \& Tourism & 8 & 0 & 3 & II \\
\hline General Linguistics & 9 & $\mathrm{I}$ & 1 & $1 \mathrm{I}$ \\
\hline Philosophy & 0 & 0 & 4 & 4 \\
\hline German & 5 & 0 & 0 & 5 \\
\hline IsiZulu Language Research \& Development Centre & 2 & 0 & 0 & 2 \\
\hline Zulu Dictionary Project & 1 & 0 & 0 & I \\
\hline TOTAL & 182 & 53 & 68 & 303 \\
\hline
\end{tabular}

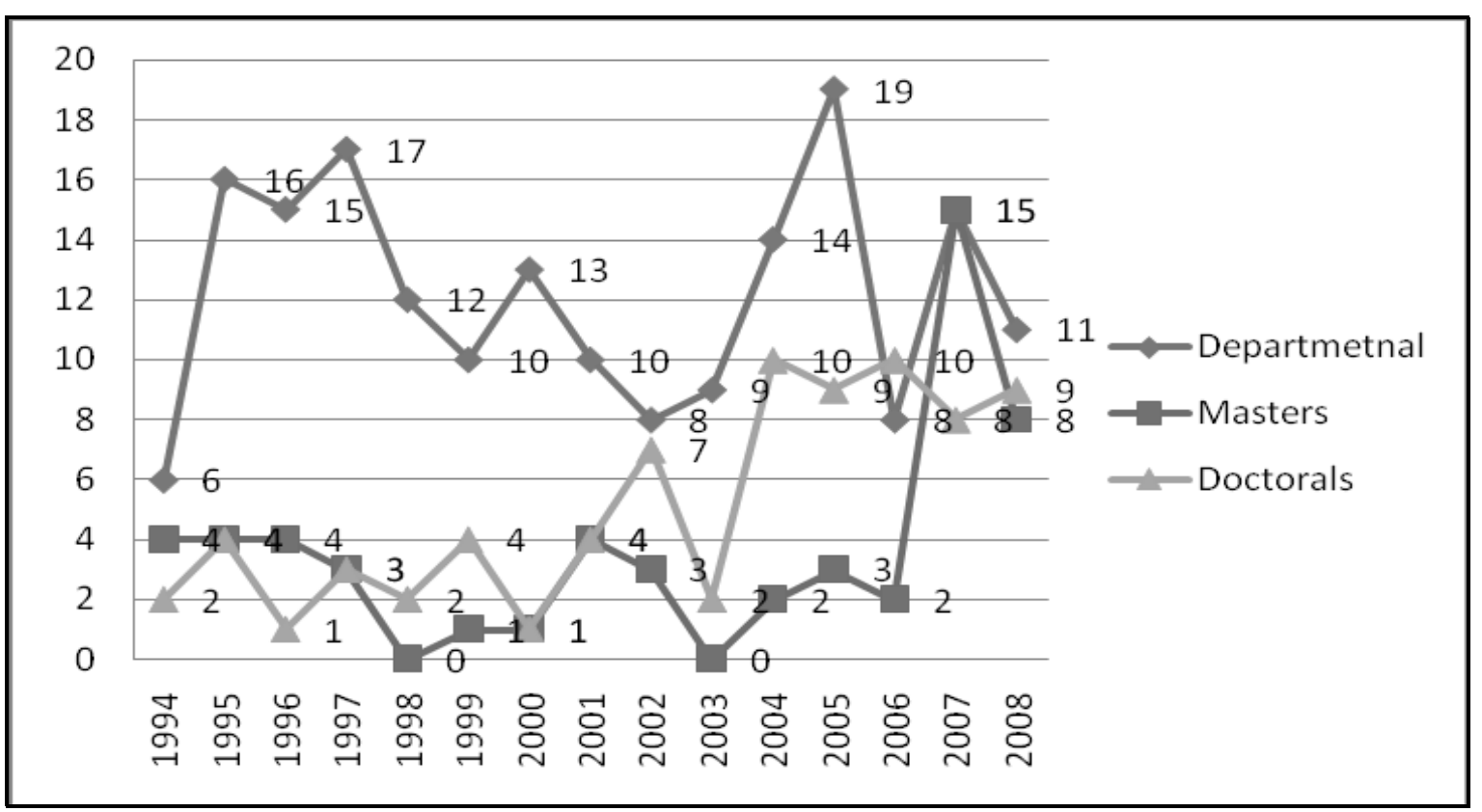

Figure 1 The volume of registered research projects by categories, 1994 - 2008

\subsection{Publication output by author}

The Faculty of Arts produced many various publications, and most of these were through research. However, some of these are not recognised as scholarly publications or research output according to the Department of Education. The Faculty of Arts' publications broadly include theses and dissertations, non-peer reviewed articles/publications, peerreviewed articles or publications, and SAPSE accredited publications. Since 1994, 965 such publications were captured by 
the Research Office. However, it is important to note that not all publications by staff were registered with the Research Office as there are no strict requirements or policing to ensure compliance. Furthermore, some staff members joined the university in the middle or towards the end of 1994 - 2008 and therefore were not obliged to submit and register the publications that they produced prior to joining the university. We also noted that it is possible that some unpublished documents submitted by staff were also registered by the Research Office as publications, which is unfortunate and calls for the thorough auditing of the research records. The most prolific authors in the faculty as registered by the Research Office from 1994 - 2008 include JM Ras (102), DN Ocholla (90), NCT Meihuizen (60), SD Edwards (52), the late JA Loubser (46), CT Moyo (3I), CA Addison (30), and MJ Hooper (29) [see Figure 2]. With the exception of Ras (II), Hooper (II) and Potgieter (I2), almost the same order of authors (Ocholla - 43, Meihuizen - 4I, Loubser 34, Edwards 33, and Addison - 19) can be found at the top of the SAPSE listing for $1994-2008$. We have also taken note of the publication output of Bosire Onyancha (now a senior lecturer at UNISA), whose research output when he was a Masters and Doctoral student (18 overall and 9 SAPSE publications for 2003 - 2007) in the Department of Information Studies, strongly suggests that with research support, students can contribute significantly to quality university research output (see Fig. 2). There were also suggestions in $1994-2008$ that there could be a correlation between overall publication output (quantitative) and SAPSE publications (qualitative).

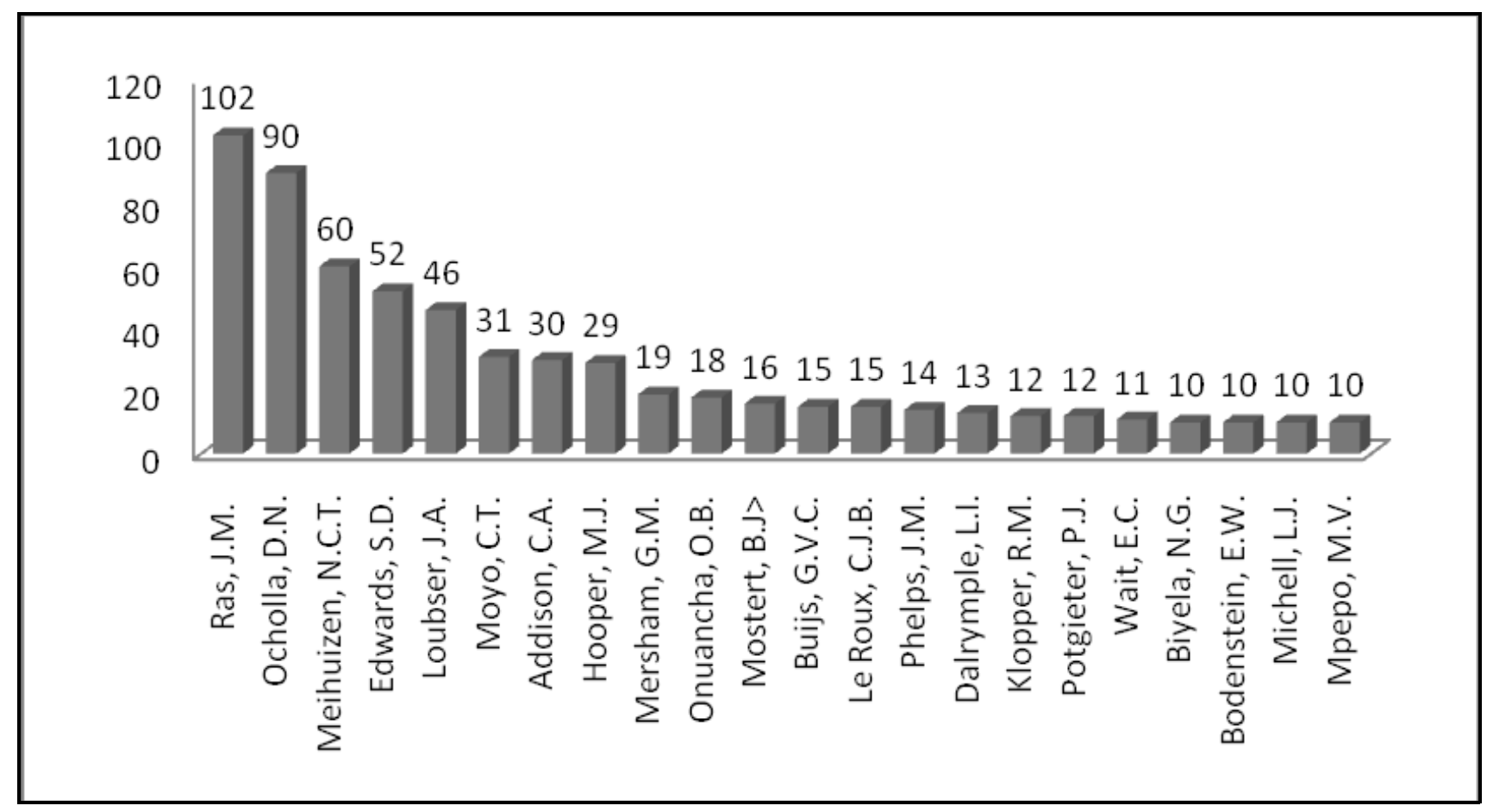

Figure 2 Authors - all publications, 1994 - 2008

\subsection{Research registration and publication output}

It is possible to check the relationships between research registration and publication output in order to account for and/ or justify research funding. Table 5 and Figure 4 present the relationships between funding and quantitative (all) and qualitative (SAPSE) publications registered by the departments in different categories.

By comparing registered projects with both publications and SAPSE output, the relationship between these activities could be gleaned. Table 5 and Figure 4 suggest that there is a relationship between registered projects and publications, but not necessarily between registered projects and SAPSE output. For example, Social Work, Centre for Arts and Culture, IsiZulu Namagugu, and the Centre for Recreation and Tourism had high research registration and a low overall number of publications and SAPSE publications compared to other departments in the Faculty. On the opposite end, Library and Information Science, English, Theology and Religious Studies, and Psychology had high publication outputs in the two categories with low research registration, suggesting that research in these departments is a cost effective and cost beneficial practice. 


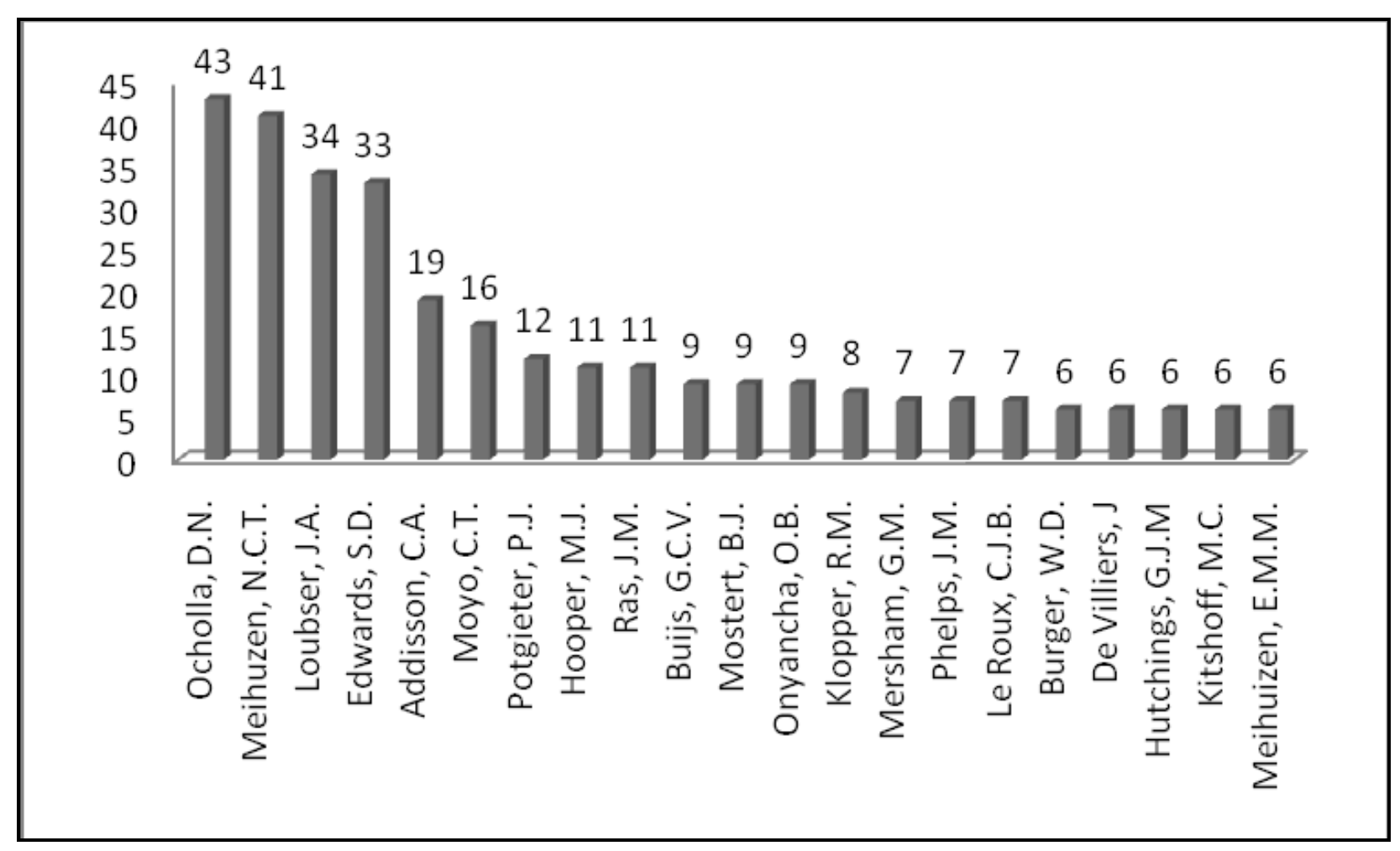

Figure 3 SAPSE publications by author

Table 5 Relationship between faculty research registration and publication output

\begin{tabular}{|c|c|c|c|c|c|c|}
\hline Department & Dept. & Ms & D & Total & Publications & SAPSE \\
\hline Library \& Information Science & 27 & 13 & 15 & 55 & 220 & 85 \\
\hline English & 17 & 4 & 5 & 26 & 170 & 100 \\
\hline Social Work & 19 & 8 & 3 & 30 & 7 & 4 \\
\hline Criminal Justice & 18 & 4 & 6 & 28 & 63 & 25 \\
\hline Centre for Arts \& Culture/dram & 19 & 4 & 2 & 25 & 13 & 5 \\
\hline Afrikaans & 5 & 0 & 4 & 9 & 35 & 27 \\
\hline Communication Science & 8 & 5 & 6 & 19 & 54 & 24 \\
\hline Sociology & 4 & 1 & 4 & 9 & 12 & 7 \\
\hline Psychology & 6 & 5 & 1 & 12 & 86 & 56 \\
\hline IsiZulu & 6 & 5 & 8 & 19 & 17 & 6 \\
\hline Theology \& Religion Studies & 17 & 0 & 5 & 22 & 154 & 70 \\
\hline History & 4 & 0 & 0 & 4 & 26 & 16 \\
\hline Anthropology \& Development Studies & 7 & 3 & 1 & 11 & 20 & 11 \\
\hline Centre for Recreation \& Tourism & 8 & 0 & 3 & 11 & 10 & 0 \\
\hline General Linguistics & 9 & 1 & 1 & 11 & 32 & 16 \\
\hline Philosophy & 0 & 0 & 4 & 4 & 26 & 17 \\
\hline German & 5 & 0 & 0 & 5 & 11 & I \\
\hline $\begin{array}{l}\text { IsiZulu Language Research \& Development } \\
\text { Centre }\end{array}$ & 2 & 0 & 0 & 2 & 8 & I \\
\hline Zulu Dictionary Project & 1 & 0 & 0 & I & 1 & I \\
\hline TOTAL & 182 & 53 & 68 & 303 & 965 & 472 \\
\hline
\end{tabular}




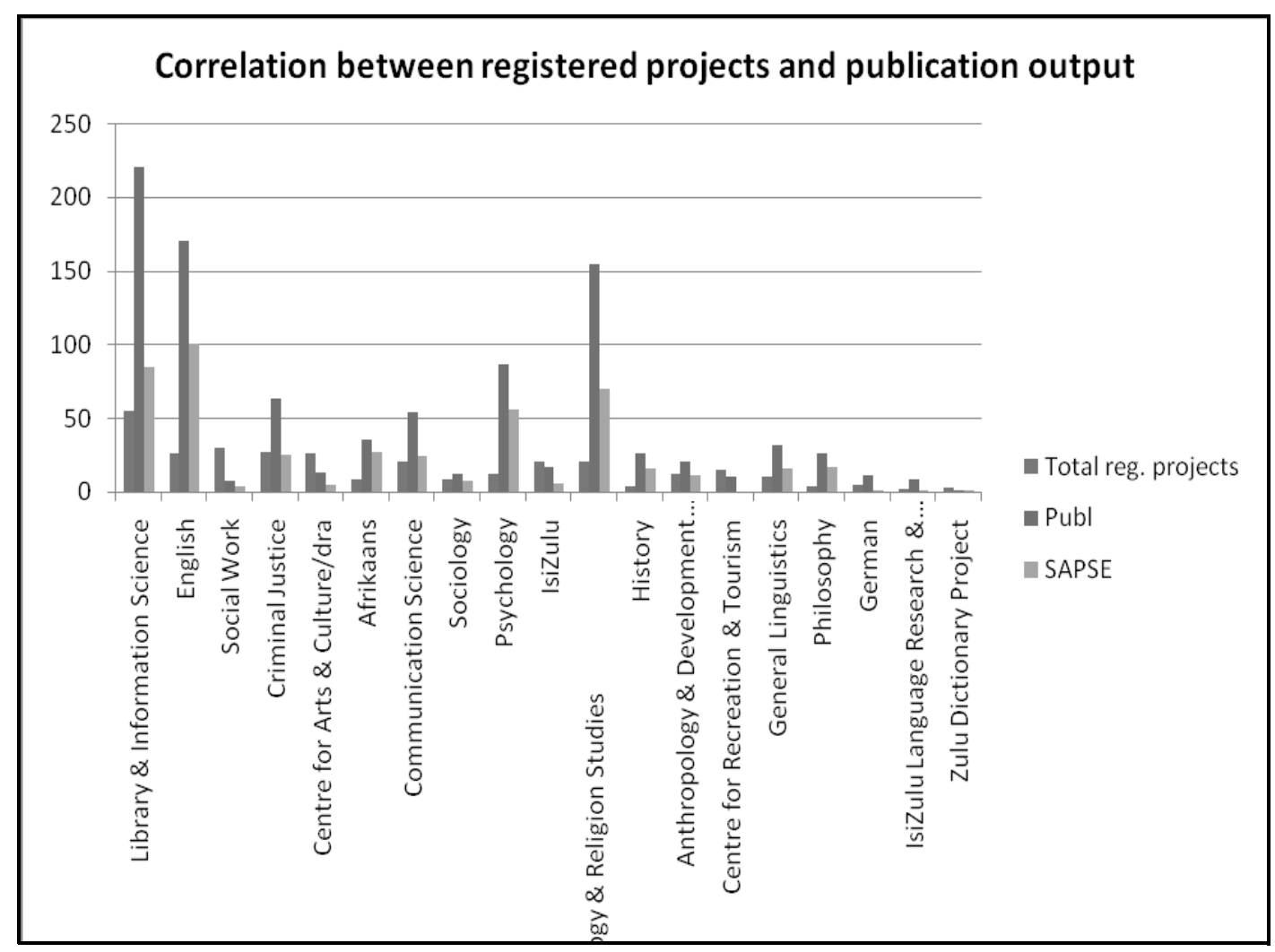

Figure 4 Relationship between research registration and publication output

Table 6 Correlation between registered research projects and publications

\begin{tabular}{|r|r|r|r|r|}
\hline & & Total Registration & Publications & SAPSE \\
\hline Total Registration & Pearson Correlation & 1 & $.711 * *$ & $.588^{* *}$ \\
\hline & Sig. (2-tailed) & $\mathbf{N}$ & .001 & .05 \\
\hline & Pearson Correlation & 19 & 19 & 19 \\
\hline Publications & Sig. (2-tailed) & $.711 * *$ & 1 & $.963 * *$ \\
\hline & $\mathbf{N}$ & .001 &. & .000 \\
\hline & & 19 & 19 & 19 \\
\hline
\end{tabular}

** Correlation is significant at the 0.01 level (2-tailed)

Using Pearson's Correlation analysis, we found a high correlation $(r=0.7 \mathrm{II})$ between the total registered projects and the total number of publications at the $0.0 \mathrm{I}$ level of significance. There is also a high correlation $(r=0.963)$ between the total registered projects and SAPSE at the $0.0 \mathrm{I}$ level of significance. It is a university research policy that every registered and university-funded research project must produce peer-refereed SAPSE publications within three years, otherwise there's no further funding.

\section{Sources of AH\&SS publications}

Research can be published in theses and dissertations, books, conference proceedings, journals, and various other publications. From 1994 to 2008 , 965 publications originating from 379 sources were produced and registered with the Research Office. Of these, 128 sources were SAPSE accredited, thus amounting to 479 publications. 450 publications originated from non-SAPSE sources. While the number of non-SAPSE sources was almost twice $(25 \mathrm{I})$ the number of 
SAPSE sources (128), publications in non-SAPSE sources were less than publications in SAPSE sources (by 29 records), meaning that scholars prefer publishing in SAPSE sources, mainly for government research subsidies and for promotion. Most of the SAPSE publications (191, 38.\%) were in 10 leading journals, including the South African Journal of Libraries and Information Science, Alteration, Acta Criminologica, Literator, English Review, Neotestamentica, SA Journal of African Languages, Indilinga - African Journal of Indigenous Knowledge Systems and English Studies Africa. We further noted that most publications were in South African sources/journals. Publications in ISI- and IBSS-indexed journals were insignificant, suggesting that most AH\&SS publications in the faculty and university generally occur in local sources. Most publications in non-SAPSE sources occurred in journals and most of these publications were not peer refereed. Journals were followed by conference proceedings, chapters in books, and books.

Table 7 Sources of publications, 1994 - 2008

\begin{tabular}{|c|c|c|c|}
\hline SAPSE Publications & & Other/Non SAPSE Sources & \\
\hline Source $(N=128)$ & Count $=479$ & Source $(\mathbf{N}=\mathbf{2 5} \mathrm{I})$ & Count $=450$ ) \\
\hline $\begin{array}{l}\text { South African Journal of Libraries and } \\
\text { Information Science }\end{array}$ & 42 & Studies on Psychology & 30 \\
\hline Alternation & 37 & $\begin{array}{l}\text { Faculty of Arts Conference: Local and Global Issues } \\
\text { in Research in Humanities and Social Sciences }\end{array}$ & 27 \\
\hline Acta Criminologica & 31 & Proceedings of DLIS 9th Annual Conference & 18 \\
\hline Literator & 22 & $\begin{array}{l}\text { Proceedings of the DLIS/LISA 6th Annual } \\
\text { Conference - Towards Popularizing LIS Research }\end{array}$ & 17 \\
\hline English Academy Review & 20 & Christianoi & 13 \\
\hline Neotestamentica & 12 & $\begin{array}{l}\text { Discussion doc on democracy, citizenship \& } \\
\text { franchise }\end{array}$ & 11 \\
\hline SA Journal of African Languages & 10 & Proceedings of DLIS 8th Annual Conference & $\mathrm{II}$ \\
\hline $\begin{array}{l}\text { Indilinga: African Journal of Indigenous } \\
\text { Knowledge Systems }\end{array}$ & 9 & $\begin{array}{l}\text { Progress in Library and Information Science in } \\
\text { Southern Africa }\end{array}$ & 9 \\
\hline English Studies in Africa & 8 & $\begin{array}{l}\text { Proceedings of the DLIS/LISA 4th Annual } \\
\text { Conference - Towards Popularizing LIS Research }\end{array}$ & 7 \\
\hline Nomina Africana & 7 & Studies on War & 7 \\
\hline Nederduits Gereformeerde Teologiese Tydskrif & 7 & International Review of Information Ethics & 6 \\
\hline Hervormde Teologiese Studies & 7 & Journal of Psychology & 6 \\
\hline Education for Information & 7 & Analecta Husserliana & 4 \\
\hline Current Writing & 7 & $\begin{array}{l}\text { Proceedings: 3rd Annual International Conference } \\
\text { of Moi University }\end{array}$ & 4 \\
\hline Studia Historiae Ecclesiasticae & 6 & The Heythrop Journal & 4 \\
\hline Stilet & 6 & English Academy Review & 3 \\
\hline $\begin{array}{l}\text { South African Journal for Research in Sport, } \\
\text { Physical Education and Recreation }\end{array}$ & 6 & GETT Propelled & 3 \\
\hline Psychological Reports & 6 & Indo-Pacific Journal of Phenomenology & 3 \\
\hline Library and Information Science Research & 6 & Inkanyezi Yokusa & 3 \\
\hline $\begin{array}{l}\text { International Journal of Mental Health } \\
\text { Promotion }\end{array}$ & 6 & L'Epoque Conradienne & 3 \\
\hline International Journal of Mental Health & 6 & Library Management & 3 \\
\hline International Information \& Library Review & 6 & LWATI: A Journal of Contemporary Research & 3 \\
\hline Tydskrif vir Letterkunde & 5 & SACOMM & 3 \\
\hline Tydskrif vir Geesteswetenskappe & 5 & Scrutiny 2 & 3 \\
\hline
\end{tabular}

\section{Conclusion and recommendations}

The overall faculty publication count was 965 for 1994 - 2008, with significant growth by almost $50 \%$ in the number of registered research projects in the last three years (with the exception of 2007). Possible reasons include increased research funding, increased dependence on publications for promotion and accountability for research output, and more collaborative publications and student involvement. We observed from the data and from our own experiences within the department that there were close ties between overall publication output and the individual productivity of a staff member; postgraduate ( $M$ and Ds) student enrolment (e.g. Library and Information Science and Psychology); participation in conferences; and joint authorship or collaboration among members of staff (such as in Psychology) or Inkanyiso, Jnl Hum \& Soc Sci 2010, 2(I) 
between staff and students (Library and Information Science). Departments with more senior staff members and whose staff turnover was low (such as English) also demonstrated better publication outputs. Most registered research projects were for non-qualification (departmental) purposes. We expected the number of registered Masters research projects (54) to be higher than Doctoral studies (70), suggesting that some Masters and Doctoral research projects may not have been registered between 1994 - 2008. It is worth checking whether all Masters and Doctoral projects are actually registered by the Research Office as research projects. Departments that registered many research projects did not necessarily produce a corresponding volume of publications, particularly SAPSE publications. There was a strong correlation between overall publication output and SAPSE publications. Most publications, appeared in a few journals, thereby confirming Bradford's Law which states that: "If scientific journals are arranged in order of decreasing productivity of articles on a given subject, they may be divided into a nucleus of periodicals more particularly devoted to the subject and several groups or zones containing the same number of articles as the nucleus, when the number of periodicals in the nucleus and succeeding zones will be as I: k: k2", where the constant k is known as Bradford's constant or multiplier (Ungern-Sternberg, 2000). Most staff members published in journals, and most of these were South African journals. Ocholla (2007) and other reports, such as the "Report on a Strategic Approach to Research Publishing in South Africa” (http://www.assaf.co.za/wp-content/uploads/reports/evidence_based/assaf_strategic_research_publishing.pdf) by the Academy of Science for South Africa (ASSAf), have argued that the large volume of publication in South African journals by South African scholars or researchers grew out of the embargo on South Africa in the past which forced the country to develop a large pool of scholarly journals (currently approximately 200) in all disciplines to encourage self reliance. This differs from the situation in other African countries where local scholarly journals are insignificant and scholars are either forced or encouraged to publish in foreign international journals for academic/research recognition and career growth. South African researchers have access to plenty of good local scholarly journals in which to publish their research output, and although publishing in foreign international journals is also encouraged, scholars in SA tend to rely more on South African journals. Increasingly, staff members publish in SAPSE accredited journals and conference proceedings. Publication in SAPSE journals is encouraged in the country by institutions of the researcher's affiliation because this helps the institution receive government research subsidies. It was also noted that a few authors published a lot of papers, which seems to confirm Alfred Lotka's law, i.e.: "For any body of literature, there will be a substantial number of authors who have each contributed only one publication, a smaller number of authors who have each contributed a small number of publications, and a very small group of authors who have each contributed a substantial number of publications" (Wallace, 1989:10). Note that it was not our intention to test either Bradford's law or Lotka's law in this instance.

We noted a few problems that relate to capturing research output at the university, such as the duplication of research documents or records, mixing published and unpublished documents, and the poor record keeping of theses and dissertations. Furthermore, more detailed codification or categorisation of research output (e.g. SAPSE/S, Non SAPSE/ NS, Conference Proceedings/CP, Book/B, Chapter in Book/CB, Peer Refereed Conference Proceedings/PRCP etc) beyond the current categories (e.g. SAPSE and Non-SAPSE) is required for easier records management.

Our future research projects will focus on: research collaboration, which is important for research capacity building; subject analysis, to help determine research orientation, niche areas and collaboration across disciplines within the faculty; the use of robust qualitative analysis techniques such as citations, the impact factor and $\mathrm{H}$-index analysis; and research visibility and presence in GS, Scopus and the Web of Science (ISI). We also hope to spread this study to other university faculties.

\section{References}

Calvert, R.J. and Gorman, G.E.2002. Testing Article Quality in LIS Journals: The Search Continues. 68'" IFLA Council and General Conference, August 18-24, code Number 169-I I8-E, Division Number VII, Library and Information Science Journals

Garfield, E. 1972. Citation analysis as a tool in journal evaluation. Science, 178, 47I-479.

Garfield, E. 1996. Citation indexes for retrieval and search evaluation. Paper presented at Consensus Conference on the Theoryand Practice of Research Assessment, Capri, October 7*, [Online] http://garfield.Hbrary.upenn.edu. Accessed 20 April 2007.

Garfield, E. 1998. The Multiple meaning of impact factors. Journal of American Society for Information Science. 49(8), 768.

Garfield, E. I97I. Publication counting vs citation counting in evaluating research. Essays of an Information Scientist, I,: I79- I8I.

Garfield, E. 1994. The ISI impact factor. Current contents June 20. [Online] http://sdentific.thomson.com/free/essays/

Gorman, G.E. 2000.Authors and Editors of Library Science Journals: Reflections from an Asian/Pacific Context. Libri, Vol.50, 98103.

Harnad, S. 1995. Implementing Peer Review on the Net: Scientific Quality Control in Scholarly Electronic Journals. In: Peek, R. \&Newby, G. (Eds.) Electronic Publishing Confronts Academia: The Agenda for the Year 2000. Cambridge MA: MIT Press. 
Harnad, Stevan. 1998. The invisible hand of peer review.[Online] [Online].Available: ftp://cogsci.ecs.soton.ac.uk]pub/harnad/ Harnad/harnad95.peerreview, http:I/www.nature.com/nature/wematters/invisible/invisible.html. accessed 22 September 2006. journalcitationreports/usingimpactfactor/ Accessed 26* May 2007

King, J. 1987. A review of bibliometric and other science indicators and their role in research evaluation. Journal of Information Science, |3,26|-276

Kostoff, R.N.(200I). Science and Technology Metrics. Retrieved May 19, 20I0, from Defence Technical Information Center. Information for Defence Community Website http://www.dtic.mil/dtic/kostoff/metweb5 iv.htm

Moed, H.F. 2005. Citation Analysis in Research Evaluation. Berlin: Springer

Ocholla, Dennis N. and Ocholla Lyudmilla (2007) Research in Library and Information Science in South Africa: an analysis of journals research output from 1993-2006. South African Journal of Libraries and Information Science, Vol.73(2), I09-I I8

Ocholla,Dennis N. and Onyancha, O. Bosire.2010. Mapping the Status of Indigenous Knowledge Research at the University of Zululand. Indilinga: African Journal of Indigenous Knowledge Systems, Vol.9, Issue I,

Onyancha, O. Bosire and Ocholla, Dennis N. (2009). Assessing Research Performance in Developing Countries: Is Google Scholar an Alternative. Mousaion, Vol.27(I), 43-64

Schmoch, Ulrich and Schubert, Torben (2009) When and how to use bibliometrics as a screening tool for research performance. Science Public Policy December 2009, 753-762.[ Online] http://www.ingentaconnect.com/content/beech/spp. Accessed, 19 May 2010

Sengupta, I.N. (1992). Bibliometrics, Informetrics, scientometrics and librametrics: An overview. Libri,42(2), 75-98 